Brazilian Journal

of Chemical

\title{
ASSESSMENT OF THE DYE REMOVAL CAPABILITY OF SUBMERSED AQUATIC PLANTS IN A LABORATORY-SCALE WETLAND SYSTEM USING ANOVA
}

\author{
O. Keskinkan ${ }^{1 *}$ and M. Z. Lugal Göksu ${ }^{2}$ \\ ${ }^{1}$ Department of Environmental Engineering, School of Engineering \& Architecture, \\ Cukurova University, Phone: +(90) (322) 3386084-2075-113, \\ Fax: +(90) (322) 3386126, 01330, Balcali/Adana, Turkey \\ E-mail: olcayto@cu.edu.tr \\ ${ }^{2}$ School of Fisheries, Cukurova University, 01330, \\ Phone: +(90) (322) 3386084-2967, Balcali/Adana, Turkey \\ E-mail: mzlg1952@cu.edu.tr \\ (Received: March 8, 2006 ; Accepted: April 02, 2007)
}

\begin{abstract}
The textile dye (Basic Blue 41(BB41)) removal capability of a laboratory-scale wetland system was presented in this study. Twenty glass aquaria were used to establish the wetland. Myriophyllum spicatum and Ceratophyllum demersum were planted in the aquaria and acclimated. After establishing flow conditions, the aquaria were fed with synthetic wastewaters containing BB41. The concentration of the dye was adjusted to $11.0 \mathrm{mg} / \mathrm{L}$ in the synthetic wastewater. Hydraulic retention times (HRTs) ranged between 3 and 18 days. Effective HRTs were 9 and 18 days. The highest dye removal rates were 94.8 and $94.1 \%$ for M. spicatum and C. demersum aquaria respectively. The statistical ANOVA method was used to assess the dye removal capability of the wetland system. In all cases the ANOVA method revealed that plants in the wetland system and HRT were important factors and the wetland system was able to remove the dye from influent wastewater.
\end{abstract}

Keywords: Constructed wetland; M. spicatum; C. demersum, Basic blue 41; Continuous flow; Hydraulic retention time.

\section{INTRODUCTION}

Constructed wetlands are engineered, man-made systems designed to treat wastewater, mine drainage, and other effluents. Constructed wetlands can provide effective, economical, and environmentallysound treatment of wastewater by optimizing biological, physical, and chemical processes that may naturally occur naturally in wetland systems.

In constructed wetlands and aquatic plant systems, the photosynthetic tissue of aquatic macrophytes is entirely submersed. These plants are able to assimilate nutrients from polluted waters. The prime potential use of submersed aquatic macrophyte-based wastewater treatment systems is "polishing" in secondary treatment effluents. The presence of these plants depletes dissolved carbon in the water and increases the content of dissolved oxygen during the periods of high photosynthetic activity. In the past decades various researchers have suggested that their prime area of application will be as a final step in multistage systems (Reed et al., 1987). The use of submersed macrophyte species, such as Egeria densa, Elodea canadensis, Elodea

*To whom correspondence should be addressed 
nuttallii, Ceratophyllum demersum, and Hydrilla verticillata is the most promising for wastewater treatment (Moshiri, 1993).

Shutes (2001) suggested that aquatic plants could be used as sewage treatment facilities. There are several studies with wetland microcosms that investigated nutrient removal (Rogers et al., 1991, Drizo et al., 1997). Heavy metal removal experimentation was also established and researchers demonstrated that macrophytes, such as Typha latifolia, Phragmites australis, Schoenoplectus lacustris, and Iris pseudacorus, can be used for heavy metal removal (Mungur et al., 1997).

On the other hand, dye-containing wastewaters are well-known pollutants of receiving bodies in industrial areas. Much focus and attention have been placed upon the removal of dyes from waste streams due to the adverse effects of dyes on the environment (see Easton et al., 1995). Dyes used by the textile industry are largely synthetic or typically derived from coal tar and petroleum-based intermediates. Each dyeing process requires a different amount of dye per unit of fabric to be dyed (EPA, 1997). BB41 is a cationic azo textile dye. Because of their resistance to wastewater treatment, some researchers have focused on azo dyes. BB41 was selected as a model compound to estimate the sorption capacity of $C$. demersum to take up basic dye from textile wastewaters. BB41 is commonly used for dyeing carpets, cottons, and other textile materials. Unless they are properly treated, textile dyes may significantly affect photosynthetic activity of aquatic life due to reduced light penetration and may also be toxic to some aquatic life (Kouba and Zhuang, 1994). Therefore, these dye materials must be removed from industrial waste waters using appropriate methods prior to discharge. Because of the low biodegradability of many textile chemicals and dyes, conventional biological treatment is not always effective for textile industry wastewater. Discoloration of textile dye effluent does not occur when treated aerobically in municipal sewerage systems (Willmott et al., 1998). The other conventional methods for treating dye-containing wastewaters are membrane filtration, coagulation, and flocculation (ASCE, 1990), reverse osmosis (Asano, 1998), and activated carbon adsorption (Wong et al., 2004). But these methods have some disadvantages for sufficient treatment. For example, activated carbon is the most popular and widely used adsorbent, but there is a certain problem with its use. It is expensive and the higher the quality, the greater the cost.

Although, wastewater treatment capability of plants that inhabit natural and constructed wetlands is known in many parts of the world, there is no information in the literature on the dye removal capability of submersed plants in a continuous flow system. Determination of the dye removal capability of submersed plants may contribute to system design approaches to constructed wetlands. Data from laboratory-scale wetland studies can be incorporated into full-scale field applications through determining the dischargeable amount of dye-containing wastewaters based on the removal performance of submersed plants. In order to discover the pollutant removal capability of submersed plant systems, researchers need to determine the amount of pollutants within the plants. One of the troublesome issues for environmental researchers is the handling of data that does not include pollutant concentrations within the plants because there is no standard dye detection method for determining the amount of dye within the plants.

In this case, it is difficult to decide which parameters affect pollutant removal in the treatment systems. Therefore, the decisions concerning which parameters affect the influent pollutant concentrations should be made with the assistance of statistical analyses. In order to assess the dye removal capacity of the submersed plant system, univariate analysis of variance (ANOVA) and Duncan homogeneity tests may be used to determine the influences of the type of wetland (namely AQUARIA), individual HRT, and [HRT $x$ AQUARIA] interaction on the influent pollutant concentrations of the wetland system. These methods build on the application of statistical and mathematical methods and include the analyses of data with many observed variables. ANOVA is the predominant statistical method that is used to interpret experimental data usually carried out using statistical software.

\section{MATERIALS AND METHODS}

Laboratory-scale wetlands were constructed in a continuous mode with 250 watt mercury lamps simulating daylight conditions. A general view of the system is shown in Fig 1.

The experiments were performed in twenty glass aquaria and a continuous flow system. River sand was placed in the bed of experimental wetland basins to hold the plants vertical. Twenty twenty-three-liter aquaria were each filled with $5 \mathrm{~kg}$ of sand. The volume of water in each aquarium was $21 \mathrm{~L}$.

Aquatic plants, $M$. spicatum and $C$. demersum, were collected from agricultural drains near the Seyhan River (Adana, Turkey). M. spicatum (water milfoil) is a submersed aquatic perennial plant and it 
is a highly invasive and aggressive species that colonizes reservoirs, lakes, ponds, streams, small rivers, and brackish waters of estuaries and bays (Fig 2a). As stems of $M$. spicatum near the water surface, they branch profusely and often form a dense canopy that reduces light availability for the other aquatic species. The spread of M. spicatum is primarily by asexual means. Long-range dispersal is primarily by fragmentation that results from mechanical breakage or autofragmentation, which occurs after flowering and at the end of the growing season. Fragments produced by either method may be transported over long distances by water currents. Once established, individual plants may expand for distances of a few meters by the production of stolons. Although $M$. spicatum produces large quantities of viable seed, very few seedlings have been observed in field situations, and seeds are considered to be of little importance in the dispersal of M. spicatum (Smith and Barko, 1990).

C. demersum (coontail) is a completely submersed plant commonly seen in a lot of lakes with moderate to high nutrient levels (Fig 2b). It grows in hard-water lakes. The tiny flowers of coon tail are located at the base of the leaves. Each is either male or female, though both are borne on the same plants. The flowers have very short stalks, so they never reach to the surface of the water. This means pollination must occur under water. It does not produce roots; instead it absorbs all the nutrients it requires from the surrounding water. When it grows near the lake bottom, it will form modified leaves which it uses to anchor itself to the sediment. However, it can float free in the water column and some times forms dense mats just below the surface (Johnson et al., 1995).

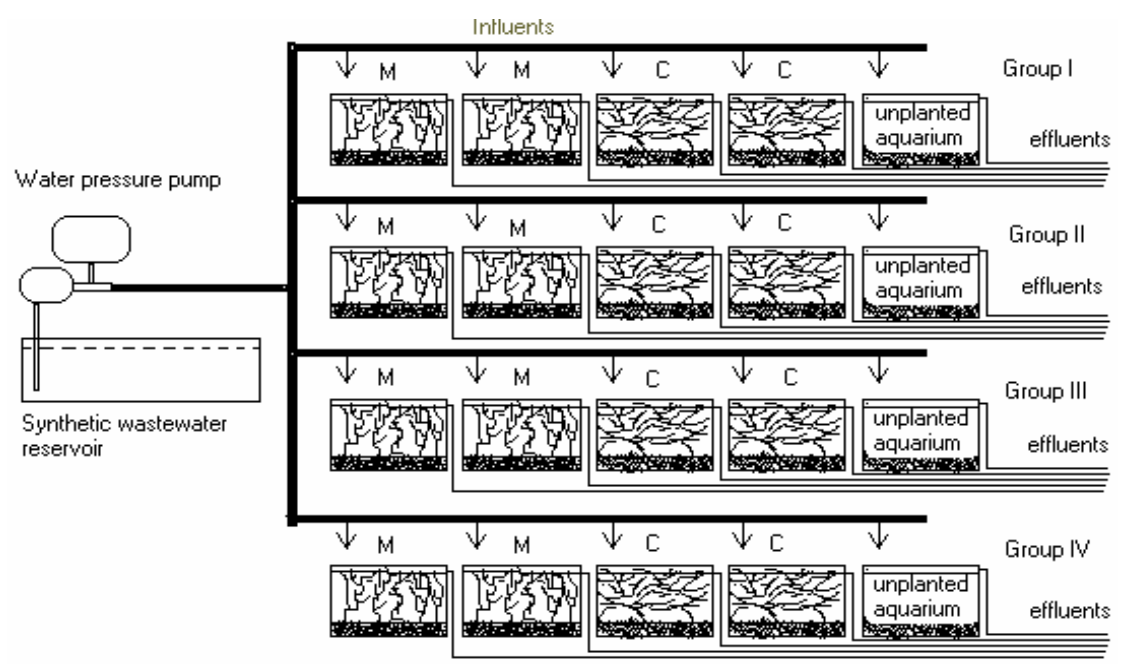

Figure 1: Scheme of the laboratory-scale constructed wetland system (M: M. spicatum aquaria, C: C. demersum aquaria, Flow rate: group I: 1.09 - 1.48 L/day, group II: $2.13-3.06$ L/day, group III: $3.83-4.26$ L/day, group IV: $6.21-8.84 \mathrm{~L} /$ day)
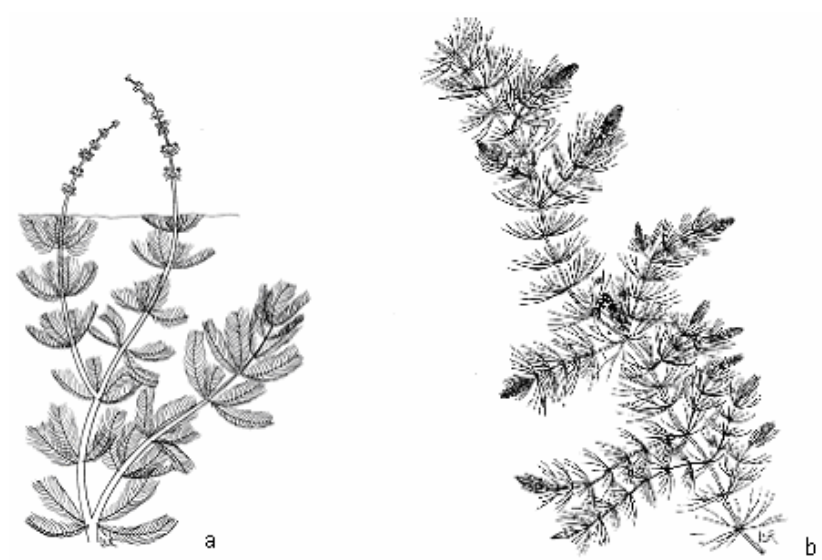

Figure 2: $M$. spicatum (a) and C. demersum (b) (illustrations provided by Institute of Food and Agricultural Sciences, Center for Aquatic and Invasive Plants, University of Florida, Miami, FL. USA) 
The plants were kept separately in cement ponds containing tap water prior to the start of the experiments. The plants were washed carefully with tap water prior to the experiments and then 16 aquaria were planted. The other four aquaria were left unplanted (control), as shown in Fig 1. The system was aerated with an air pump in order to keep the dissolved oxygen levels $(>5 \mathrm{mg} / \mathrm{L})$ in the aquaria high. Before application of the dye, the planted and control aquaria were loaded with Arnon-Hoagland (Table 1) 5\% nutrient solution at a maximum hydraulic loading rate of $6.21-8.84 \mathrm{~L} /$ day, which corresponds to the lowest hydraulic retention time of approximately 3 days.

The aquaria were left to for acclimate for two weeks. HRTs were then adjusted to 3 to 18 days, as shown in Table 2.

Table 1: Contents of the Arnon-Hoagland nutritive solution

\begin{tabular}{|l|c|}
\hline Components & Concentrations (mg/L) \\
\hline $\mathrm{KNO}_{3}$ & 1020.00 \\
$\mathrm{Ca}\left(\mathrm{NO}_{3}\right)_{2}$ & 492.00 \\
$\mathrm{NH}_{4} \mathrm{H}_{2} \mathrm{PO}_{4}$ & 230.00 \\
$\mathrm{MgSO}_{4} \cdot 7 \mathrm{H}_{2} \mathrm{O}$ & 420.00 \\
$\mathrm{H}_{3} \mathrm{BO}_{3}$ & 2.86 \\
$\mathrm{MnCl}_{2} \cdot 4 \mathrm{H}_{2} \mathrm{O}$ & 1.81 \\
$\mathrm{H}_{2} \mathrm{MoO}_{4} \cdot \mathrm{H}_{2} \mathrm{O}$ & 0.09 \\
$\mathrm{FeSO}_{4} \cdot 7 \mathrm{H}_{2} \mathrm{O}$ & 0.07 \\
$(\mathrm{CHOH})_{2}(\mathrm{COOH})_{2}$ & 0.02 \\
\hline
\end{tabular}

Table 2: Hydraulic retention times in the aquaria according to hydraulic loading rate

\begin{tabular}{|c|c|c|}
\hline Group & $\begin{array}{c}\text { Hydraulic loading rate } \\
\text { (L/day) }\end{array}$ & $\begin{array}{c}\text { Hydraulic retention time } \\
\text { (days) }\end{array}$ \\
\hline I & $1.09-1.48$ & $18.25 \pm 2.75 \cong 18$ \\
II & $2.13-3.06$ & $9.15 \pm 1.65 \cong 9$ \\
III & $3.83-4.26$ & $5.70 \pm 0.30 \cong 6$ \\
IV & $6.21-8.84$ & $3.25 \pm 0.65 \cong 3$ \\
\hline
\end{tabular}

The synthetic wastewater used in this study was prepared using a mixture of Arnon-Hoagland nutrients and dye (Basic Blue 41-BB41, C.I. No. 11105), providing a $11.0 \mathrm{mg}$ BB41/L concentration. The structure of the dye used is as shown in Figure 3. Each aquarium was connected to a $150-\mathrm{L}$ wastewater reservoir tank, which contained a mixture of $11.0 \mathrm{mg} / \mathrm{L}$ BB41 and $5 \%$ Arnon-Hoagland nutrients. Via a water pressure pump, flow of the synthetic wastewater into the aquaria was provided. At the same time dye concentrations in all aquaria were adjusted to 11.0 mg BB41/L using the synthetic wastewater prior to starting the experiment.<smiles></smiles>

Figure 3: Structure of BB41 (C.I. No. 11105) (Adapted from Baran et al., 2003)

Regarding hydraulic loadings, dye loading rates were then calculated as 136.25 to 1105.00 $\mathrm{mg} / \mathrm{m}^{2}$ day. Dissolved oxygen concentrations and $\mathrm{pH}$ values were measured with an oxygen meter (YSI 51B) and a $\mathrm{pH}$ meter (Hanna instrument $\mathrm{pH} 211$ ).
Samples were collected from effluent of each aquarium on the $10^{\text {th }}, 20^{\text {th }}, 30^{\text {th }}$, and $40^{\text {th }}$ days after the loading of synthetic wastewater. The samples were centrifuged and supernatants were then analyzed to determine the dye concentrations. 
Samples were analyzed with a light spectrophotometer (Bausch-Lomb) at a $609 \mathrm{~nm}$ wavelength to determine the dye concentrations. After analyses, removal efficiency was calculated to determine the performance of the system. Dye concentration in the plants could not be determined because there is no standard dye detection method to demonstrate the amount of dye within the plants. Therefore, in order to determine which parameters affect the influent pollutant concentrations, a univariate ANOVA test was used to test the null hypothesis that type of wetland (planted and unplanted aquaria called AQUARIA) has no significant effect on pollutant removal. The method was also used to test the null hypothesis that the individual HRT and [AQUARIA $x$ HRT] interaction have no significant effect on pollutant removal. Furthermore, when $F$-values were significant, Duncan's homogeneity of variance test was performed to identify differences between means of constituent data groups. It was used to test the null hypothesis that mean dye concentrations in aquaria effluents were consistent with each other.

\section{RESULTS AND DISCUSSION}

In all cases, dissolved oxygen concentration was never below $5.1 \mathrm{mg} / \mathrm{L}$ (Fig 4). $\mathrm{pH}$ values in the aquaria remained at 6.5 to 7.9 throughout the experimental period (Fig 5). The values obtained for the effluents were almost equal to the influent $\mathrm{pH}$.

The results shown below indicates that the effluent dye concentrations at HRTs of 9 and 18 days were lower than those at HRTs of 3 and 6 days (Tables 3 and 4).

A summary of the results obtained by the univariate ANOVA, which reflect the dye removal capability of the wetland system is presented in Table 5.

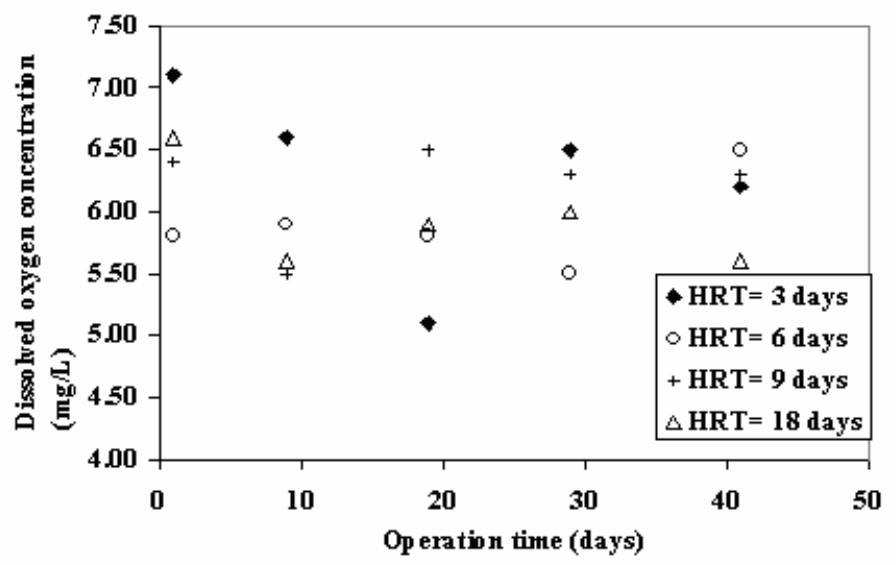

Figure 4: Change in dissolved oxygen concentrations during the study

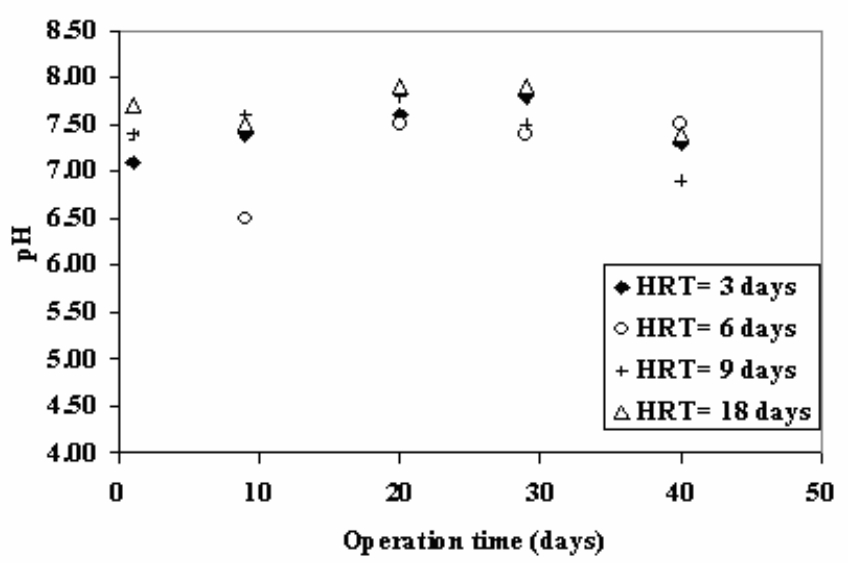

Figure 5: Change in $\mathrm{pH}$ values during the study 
Table 3: Effluent dye concentrations of the laboratory-scale wetland system (influent concentration: $11.0 \mathrm{mg} / \mathrm{l}$ )

\begin{tabular}{|c|c|c|c|c|c|c|c|c|}
\hline \multirow{4}{*}{ Type of wetland } & \multicolumn{8}{|c|}{ HRT (days) } \\
\hline & \multicolumn{4}{|c|}{3} & \multicolumn{4}{|c|}{6} \\
\hline & \multicolumn{4}{|c|}{ Monitoring time (days) } & \multicolumn{4}{|c|}{ Monitoring time (days) } \\
\hline & $10^{\text {th }}$ & $20^{\text {th }}$ & $30^{\text {th }}$ & $40^{\text {th }}$ & $10^{\text {th }}$ & $20^{\text {th }}$ & $30^{\text {th }}$ & $40^{\text {th }}$ \\
\hline M.spicatum + sand & 3.30 & 2.92 & 3.15 & 4.35 & 3.30 & 3.20 & 3.00 & 3.20 \\
\hline C. demersum + sand & 3.42 & 3.15 & 3.00 & 3.80 & 3.20 & 3.36 & 3.40 & 4.20 \\
\hline Control (only sand) & 4.97 & 3.87 & 3.55 & 3.34 & 4.61 & 3.55 & 3.34 & 3.56 \\
\hline
\end{tabular}

Table 4: Effluent dye concentrations of the laboratory-scale wetland system (influent concentration: $11.0 \mathrm{mg} / \mathrm{l}$ )

\begin{tabular}{|c|c|c|c|c|c|c|c|c|}
\hline \multirow{4}{*}{ Type of wetland } & \multicolumn{8}{|c|}{ HRT (days) } \\
\hline & \multicolumn{4}{|c|}{9} & \multicolumn{4}{|c|}{18} \\
\hline & \multicolumn{4}{|c|}{ Monitoring time (days) } & \multicolumn{4}{|c|}{ Monitoring time (days) } \\
\hline & $10^{\text {th }}$ & $20^{\text {th }}$ & $30^{\text {th }}$ & $40^{\text {th }}$ & $10^{\text {th }}$ & $20^{\text {th }}$ & $30^{\text {th }}$ & $40^{\text {th }}$ \\
\hline M.spicatum+sand & 0.96 & 0.81 & 1.03 & 0.82 & 1.16 & 0.47 & 0.35 & 0.43 \\
\hline C. demersum + sand & 0.85 & 0.82 & 0.92 & 0.90 & 0.50 & 0.65 & 0.50 & 0.65 \\
\hline Control (only sand) & 4.85 & 3.53 & 3.53 & 3.44 & 4.24 & 3.24 & 3.24 & 3.21 \\
\hline
\end{tabular}

Table 5: Results of the univariate ANOVA of the effluent dye concentrations

\begin{tabular}{|l|c|c|}
\hline Source & F & Sig. \\
\hline AQUARIA & 74.895 & 0.000 \\
HRT & 65.325 & 0.000 \\
AQUARIA * HRT & 13.144 & 0.000 \\
\hline
\end{tabular}

Because the significance values are lower than 0.05 , the null hypothesis was rejected. In Table 5 significance values clearly show that HRT, AQUARIA, and interaction between HRT and AQUARIA are parameters the influencing dye removal capability of the wetland system. It should be noted that the $F$-value obtained for AQUARIA is higher than that of HRT and HRT $x$ AQUARIA interaction. Therefore it can be stated that the parameter AQUARIA has much more effect on dye removal efficiency than the other parameters in the wetland system.

Figures 6 to 9 reflect the effect of submersed plants on the dye removal capability of the wetland system. In Figures 6 to 9 it can be seen that mean dye concentrations of the planted aquaria effluents at HRTs of 9 and 18 days are lower than those of the unplanted aquaria effluents at HRTs of 3 and 6 days.

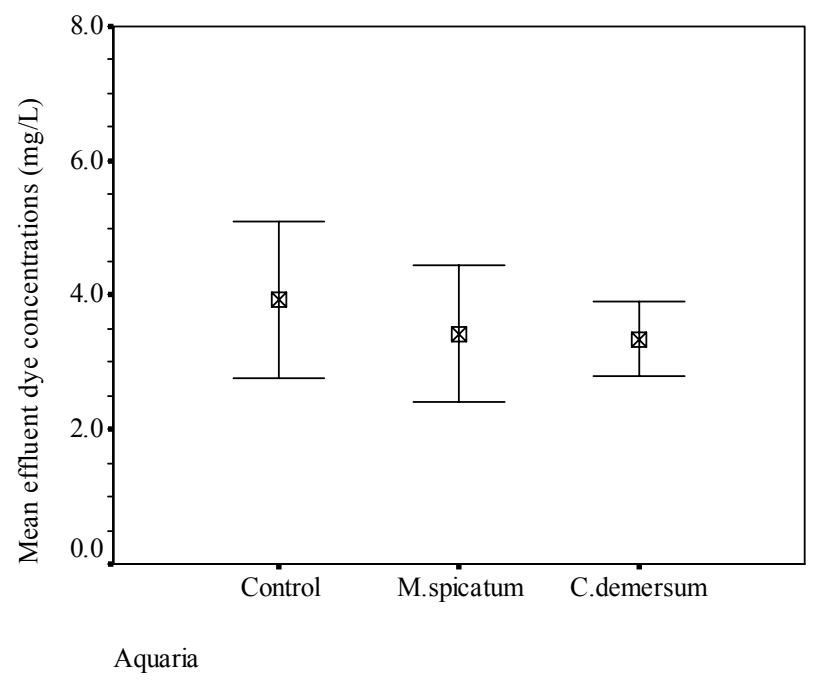

Figure 6: Effect of submersed plants on the dye removal capability of the wetland system at an HRT of 3 days (Influent dye concentration: $11.0 \mathrm{mg} / \mathrm{L}$ ) 


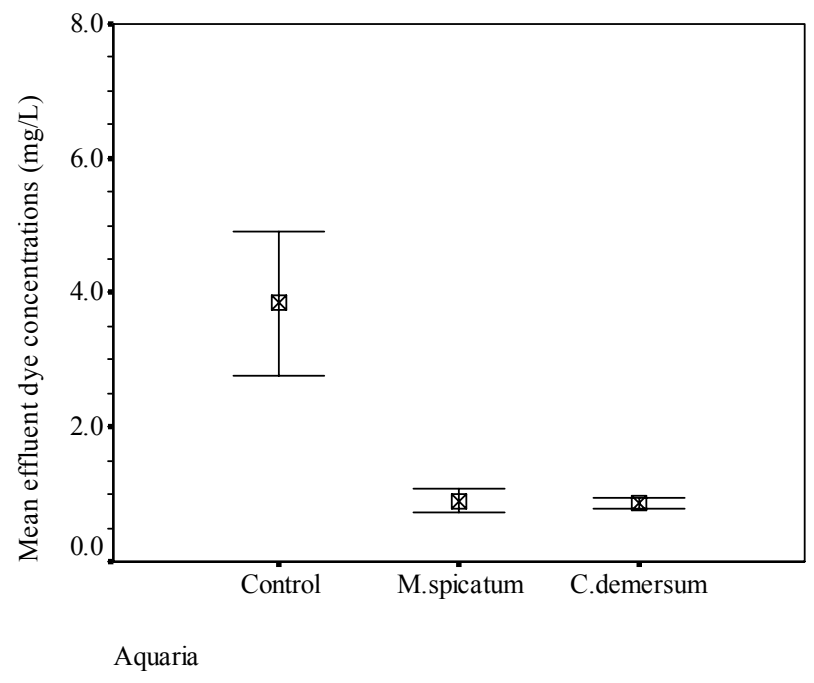

Figure 7: Effect of submersed plants on the dye removal capability of the wetland system at an HRT of 6 days (Influent dye concentration: $11.0 \mathrm{mg} / \mathrm{L}$ )

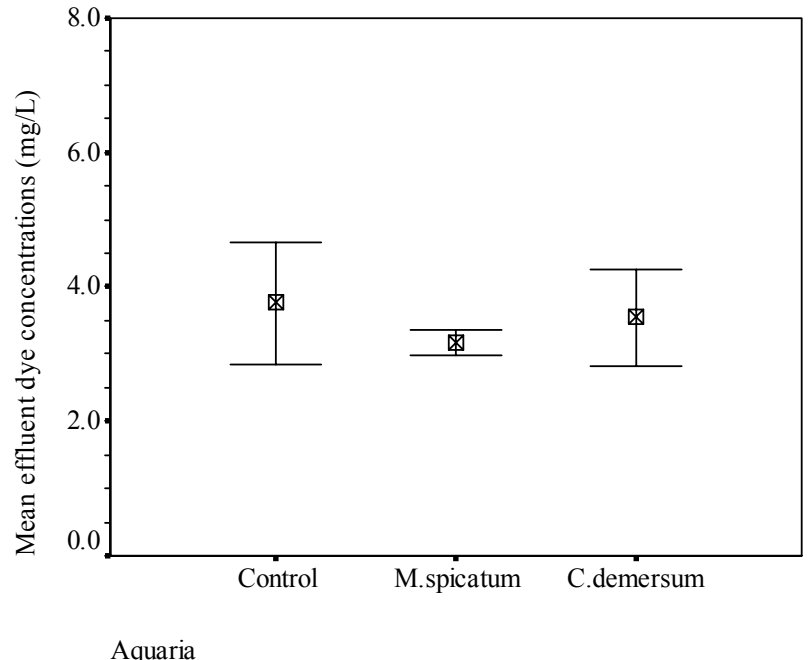

Figure 8: Effect of submersed plants on the dye removal capability of the wetland system at an HRT of 9 days (Influent dye concentration: $11.0 \mathrm{mg} / \mathrm{L}$ )

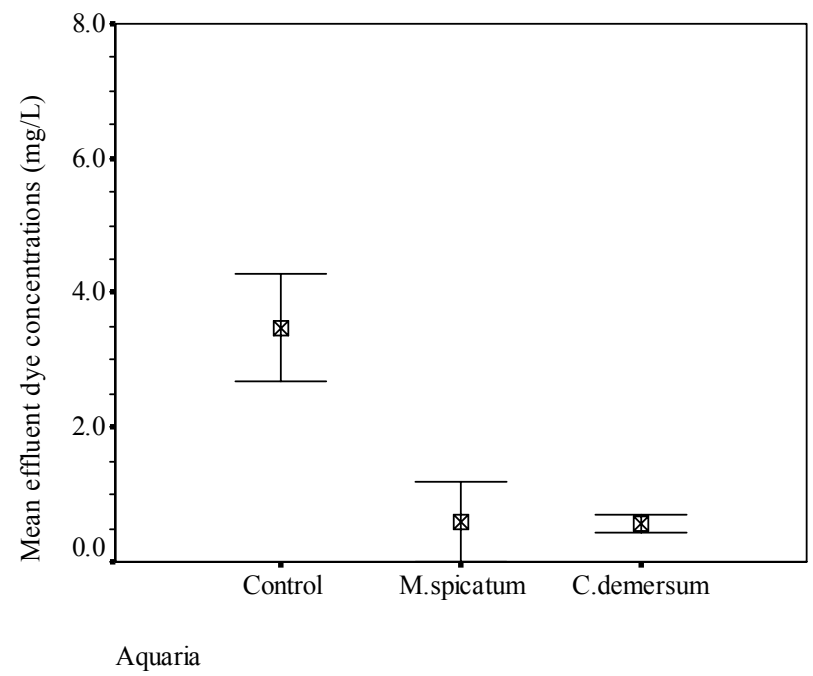

Figure 9: Effect of submersed plants on the dye removal capability of the wetland system at an HRT of 18 days (Influent dye concentration: $11.0 \mathrm{mg} / \mathrm{L}$ ) 
The dye concentrations of the effluents of $M$. spicatum and $C$. demersum aquaria were reduced from $11.0 \mathrm{mg} / \mathrm{L}$ to 0.43 and $0.65 \mathrm{mg} / \mathrm{L}$ respectively. The highest dye removal rates were 94.8 and $94.1 \%$ for the $M$. spicatum and $C$. demersum aquaria respectively. Furthermore, the highest dye removal rate in unplanted aquaria was $70.8 \%$. These results show that the effect of both plants on dye removal rate was approximately $24.0 \%$.

The statistical method that was used in this study also described the influence of the type of wetlands (the effect of plants) on the pollutant removal process. For this purpose a post hoc comparison (Duncan) test was used (Table 6). The significance value in Table 6 indicates that the null hypothesis should be accepted. The meaning of this acceptance points out that the variances of the effluent zinc concentrations of the $M$. spicatum and $C$. demersum aquaria were homogeneous as the test put both plants in the same subset.

Table 6: Results of the Duncan homogeneity test demonstrating the effect of plants

\begin{tabular}{|l|c|c|c|}
\hline \multirow{2}{*}{ AQUARIA } & \multirow{2}{*}{ N } & $\mathbf{1}$ & \multicolumn{2}{|c|}{ Subset } \\
\cline { 3 - 4 } & 16 & 2.0281 & $\mathbf{2}$ \\
\hline M.spicatum & 16 & 2.0825 & 3.7544 \\
C.demersum & 16 & & \\
Sig. & & 0.737 & 1.000 \\
\hline
\end{tabular}

The statistical method in this study was not used solely to describe the influence of the type of wetlands, but rather to verify the capability of the method to predict the effect of HRT on the pollutant removal process. The terms shown in the Figures 6 to 9 reflect relations between HRT and effluent mean dye concentrations.

It can be seen that, for a given set of inputs, the statistical analysis selected HRT as an influencing parameter for the dye removal capability of the wetland system. According to the ANOVA tests for a confidence level of $95 \%(p<0.05)$, there were no significant differences in average dye concentrations of the aquaria effluents at HRTs of 3 and 6 days. At HRTs of 9 and 18 days, there were significant differences in average dye concentrations of the aquaria effluents and removal efficiencies were significantly higher $(p<0.05)$ than those at HRTs of 3 and 6 days. Regarding dye loading rates, the amounts of dye removed from the synthetic wastewater for HRTs of 9 and 18 days were calculated as 129.16-311.42 and 128.21-309.11 $\mathrm{mg} / \mathrm{m}^{2}$ day in $M$. spicatum and $C$. demersum aquaria, respectively. Figures 6 to 9 strongly suggest that the increase in HRT affected the dye removal performance of the wetland system. The post hoc comparison (Duncan) test indicated that differences between means of constituent data groups for HRTs of 3 and 6 and 9 and 18 days were statistically significant $(p<0.05)$ (Table 7).

Table 7: The differences between means of constituent data groups according to the post hoc comparison test

\begin{tabular}{|r|r|r|r|}
\hline HRT & \multirow{2}{*}{ N } & \multicolumn{2}{|c|}{ Subset } \\
\cline { 3 - 4 } & 12 & 1.5533 & $\mathbf{2}$ \\
\hline 18 & 12 & 1.8717 & - \\
6 & 12 & - & 3.4933 \\
3 & 12 & - & 3.5683 \\
Regressions $\left(\mathrm{R}^{2}\right)$ & 0.95 & 0.85 & 0.93 \\
\hline
\end{tabular}

The Lower dye concentrations in planted aquaria with the increase in HRT, reflect that HRT has a significant influence on dye removal. When HRT was increased from 3 and 6 days to 9 and 18 days, the plants were much more important.

Neither M. spicatum nor $C$. demersum was able to survive at the lower HRTs ( 3 and 6 days) and plants survived at the higher HRTs (9 and 18 days) in the overall aquaria study. Thus, it is possible to say that living plants are more effective in dye removal at HRTs of 9 and 18 days. These results indicate that low HRTs may be hazardous to all plant species.

Beside the very rare of the laboratory-scale wetland studies, there is no data on textile dye 
removal by $M$. spicatum and $C$. demersum in any continuous flow system. Sapari (1996) focused on some locally common plants (Axonopus affinis and Panicum maximum) in Malaysia and showed that both plants can be used in a laboratory-scale wetland system as tertiary treatment. Although dye removal rates were not studied, it was shown that the wetland system achieved high BOD and COD removal rates preceded by conventional biological treatment in the study. In this study, as is the case in the study by Sapari, (1996), it is possible to say that wetland systems planted with appropriate species can be used for the treatment of textile wastewaters. Furthermore, Waranusantigul et al., (2003) reported that the dry biomass of a floating aquatic plant, Spirodela polyrrhiza, can be used for dye (methylene blue) removal in a batch system by adsorption. In the literature, it can be seen that the dye removal capability of wetland systems with aquatic submersed plants has not received any attention.

Considering the ANOVA and post hoc tests, there are several potential explanations for removal mechanisms. First of all, the difference between planted and control aquaria shows that dye was captured by plants. Secondly, although high removal rates were obtained in the planted aquaria, the removal rate in the control aquaria can not be neglected. Consequently, the statistical ANOVA test results indicated that both $M$. spicatum and $C$. demersum can be important factors in dye removal. Observing higher removal rates in the planted aquaria with the increase in HRT reflects that HRT is also an important factor. When HRT was increased from 3 and 6 days to 9 and 18 days, the plants were much more important. The plants used in the system may help the polishing processes. In laboratory-scale studies, the role of the plants and other factors in constructed wetlands can be shown with the assistance of ANOVA tests.

\section{CONCLUSIONS}

Each aquarium in the laboratory-scale wetland system removed textile dye from the synthetic wastewater in this study. High dye removal efficiencies were obtained and wetland plants remained alive at HRTs of 9 and 18 days, which corresponds to the lowest loading rates. The results presented here demonstrate that the presence of $M$. spicatum and $C$. demersum in the laboratory-scale wetland system contributed significantly to the treatment of textile dye at various loading rates. Based on univariate ANOVA, statistical test results showed that there was a significant difference in dye concentrations between planted and unplanted aquaria effluents and planted aquaria had higher dye treatment efficiencies than the unplanted aquaria. Variation in HRT was an important factor in dye treatment such that the treatment performance increased with increasing HRT. Dye removal rates of the plant species were statistically similar. In conclusion, $M$. spicatum and $C$. demersum systems can be used to treat low concentrations of dye from wastewater in a continuous flow wetland treatment system.

\section{NOMENCLATURE}

$\begin{array}{ll}\text { BB41 } & \text { Basic Blue } 41 \\ \text { HRT } & \text { Hydraulic retention time } \\ \text { ANOVA } & \text { Analysis of variance } \\ \text { AQUARIA } & \text { Type of wetland }\end{array}$

\section{ACKNOWLEDGEMENTS}

This study was financially supported by the Çukurova University Research Foundation (Project No: FBE.2002.D18).

\section{REFERENCES}

Asano T., Water Quality Management Library, Wastewater Reclamation and Reuse, vol. 10. Technomic Publishing Company, Pennsylvania, USA (1998).

ASCE \& AWWA, American Society of Civil Engineers and American Water Works Association. Water treatment plant design. 2nd Ed. In: Harold B., Crawford, Gretlyn C., editors. New York: McGraw-Hill (1990).

Baran W., Makowski A., and Wardas W., The influence of $\mathrm{FeCl} 3$ on the photocatalytic degradation of dissolved azo dyes in aqueous $\mathrm{TiO}_{2}$ suspensions. Chemosphere, 53, 87-95 (2003).

Drizo A., Frost C.A., Smith K.A., and Grace J., Phosphate and ammonium removal by constructed wetlands with horizontal subsurface flow using shale as a substrate. Water Science and Technology. 35 (5), 95-102 (1997).

Easton J.R., Waters B.D., Churchley J.H., and Harrison J., in: Cooper P. (Eds.), Colour in dyehouse effluent, Society of Dyers and Colourists, The Alden Press, Oxford, 1995, p.9. 
EPA (Environmental Protection Agency), Profile of the Textile Industry, Office of compliance sector notebook project (EPA/310-R- 97-009), Washington, DC (1997).

Hoagland D.R. and Arnon D.I., The water culture methods for growing plants without soil., Calif. Agric. Exp. Stn. Crc. 347, 1-39 (1950).

IFAS (Institute of Food and Agricultural Sciences), Center for Aquatic and Invasive Plants University of Florida, USA. (2005).

Johnson D., Kershaw L., MacKinnon A., and Pojar J., Plants of Western Boreal Forest and Aspen Parkland. Lone Pine Publishing, Vancouver, BC (1995).

Kouba J.F. and Zhuang P., Color removal for textile dyeing wastewater. Fluid/Particle Seperation Journal. 7, 87-90 (1994).

Moshiri G.A., Constructed wetlands for water quality improvement. Lewis Publishers, CRC Press, Inc., Florida (1993).

Mungur A.S., Shutes R.B.E., Revitt D.M., and House M.A., An assessment of metal removal by a laboratory scale wetland. Water Science and Technology, 35(5), 125-133 (1997).

Reed S.C., Middlebrooks E.J., and Crites R.W., Natural systems for waste management and treatment, McGraw-Hill Book Co., New York (1987).
Rogers K.H., Breen P.F., and Chick A.J., Nitrogen removal in experimental wetland treatment systems: Evidence for the role of the aquatic plants. Research Journal Water Pollution Control Federation. 63, 934-941 (1991).

Sapari N., Treatment and reuse of textile wastewater by overland flow. Desalination. 106, 179-182 (1996).

Shutes R.B.E., Artificial wetlands and water quality improvement. Environment International, 26, 441-447 (2001).

Smith C.S. and Barko J.W. Ecology of Eurasian water milfoil. Journal of Aquatic Plant Management 28: 55-64 (1990).

Waranusantigul P., Pokethitiyook P., Kruatrachue M., and Upatham E.S., Kinetics of basic dye (methylene blue) biosorption by giant duckweed (Spirodela polyrrhiza) Environmental Pollution, 125(3), 385-392 (2003).

Willmott N., Guthrie J., and Nelson G., The biotechnology approach to colour removal from textile effluent, Journal of the Society of Dyers and Colourists, 114 (2), 38-41 (1998).

Wong Y.C., Szeto Y.S., Cheung W.H., and McKay G., Adsorption of acid dyes on chitosan equilibrium isotherm analyses. Process Biochemistry. 39(6):695-704 (2004). 